\title{
OÚRICURI
}

\section{DIVERGÊNCIA GENÉTICA ENTRE ACESSOS DE GUARANAZEIRO POR MEIO DE DESCRITORES MORFOLÓGICOS}

\author{
Matheus Almeida Machado SILVA ${ }^{1}$; Emmanoel BARBOSA ${ }^{2}$; José Raimundo dos Reis SILVA ${ }^{3}$; \\ Miguel Julio Machado GUIMARÃES ${ }^{*}$
${ }_{1}^{1}$ Programa de Pós-graduação em Recursos Genéticos Vegetais Universidade Federal do Recôncavo da Bahia, Cruz das Almas, matheusamachado@hotmail.com
2Programa de Pós-graduação em Ciências Agrárias, Universidade Federal do Recôncavo da Bahia, Cruz das Almas, emmanoelemo@yahoo.com.br
3Programa de Pós-graduação em Ciências Agrárias, Universidade Federal do Recôncavo da Bahia, Crus das Almas, josereisilva1@hotmail.com
${ }^{4}$ Bolsista PDTCR FACEPE/CNPq, Embrapa Semiárido, Petrolina-PE. *Autor correspondente. E-mail: mjmguimaraes@hotmail.com
Recebido: 30.09.2020 Aceito: 22.12.2020 \\ https://doi.org/10.29327/ouricuri.10.1-7
}

\begin{abstract}
Resumo: O guaranazeiro é cultivado no baixo sul da Bahia, tornando o estado maior produtor do país. O cultivo é de grande importância socioeconômica para região em virtude de ser explorado por pequenas propriedades e por ser uma atividade típica de agricultura familiar. Dezoito caracteres qualitativos, foram utilizados para avaliação de 11 acessos de guaranazeiro (Paullinia cupana). Este trabalho teve como objetivo avaliar a diversidade genética entre os acessos, bem como detectar os caracteres que mais contribuíram para divergência genética entre os mesmos. Para a identificação dos descritores com maior contribuição foi utilizado coeficiente de entropia de Renyi. Na análise de agrupamento foi utilizado o método UPGMA, a medida de distância usada foi a de Cole-Rodgers e para definição do número de grupos, foi usado o índice pseudot ${ }^{2}$. Os descritores que mais contribuíram para divergência entre os acessos estudados foram o comprimento do racemo, coloração verde da folha, forma da folha, comprimento dos ramos, arquitetura da planta, densidade de frutos no racemo e o tamanho do fruto (TAM-FRUT). Os acessos mais divergentes foram o AP3 e o A-P2.
\end{abstract}

Palavras-chave: Paullinia cupana; Melhoramento Genético; Diversidade.

\section{GENETIC DIVERGENCE BETWEEN GUARANA ACCESS THROUGH MULTIVARIATE TECHNIQUES}

\begin{abstract}
The guaranazeiro is cultivated in the lower south of Bahia, making it the largest producer state in the country. The cultivation is of great socioeconomic importance for the region because it is exploited by small properties and because it is a typical activity of family agriculture. Eighteen qualitative characters were used to evaluate 11 accesses of guaranazeiro (Paullinia cupana). This work aimed to evaluate the genetic diversity among the accesses, as well as to detect the traits that most contributed to genetic divergence among them. Renyi's entropy coefficient was used to identify the descriptors with the highest contribution. In the grouping analysis the UPGMA method was used, the distance measurement used was that of Cole-Rodgers and to define the number of groups the pseudot $^{2}$ index was used. The descriptors that most contributed to the divergence between the studied accesses were the raceme length, green leaf coloration, leaf shape, length of branches, plant architecture, density of fruits in the raceme and fruit size (TAM-FRUT). The most divergent accesses were A-P3 and A-P2.
\end{abstract}

Revista Ouricuri, Juazeiro, Bahia, v.10, n.1. p.027-037. jan./jul., 2020.

http://www.revistas.uneb.br/index.php/ouricuri | ISSN 2317-0131 
Keyword: Paullinia cupana; Genetic Improvement; Diversity.

\section{DIVERGENCIA GENÉTICA ENTRE LOS ACCESOS DEL GUARANAZEIRO POR DESCRIPTORES MORFOLÓGICOS}

Resumen: El guaranazeiro se cultiva en el bajo sur de Bahía, lo que lo convierte en el mayor estado productor del país. El cultivo tiene una gran importancia socioeconómica para la región porque es explotado por pequeñas propiedades y porque es una actividad típica de la agricultura familiar. Se utilizaron 18 caracteres cualitativos para evaluar 11 accesos de guaranazeiro (Paullinia cupana). Esta labor tenía por objeto evaluar la diversidad genética entre los accesos, así como detectar los rasgos que más contribuían a la divergencia genética entre ellos. El coeficiente de entropía de Renyi se utilizó para identificar los descriptores con mayor contribución. En el análisis de agrupación se utilizó el método UPGMA, la medición de distancia utilizada fue la de Cole-Rodgers y para definir el número de grupos se utilizó el índice pseudot ${ }^{2}$. Los descriptores que más contribuyeron a la divergencia entre los accesos estudiados fueron la longitud del racimo, la coloración verde de las hojas, la forma de las hojas, la longitud de las ramas, la arquitectura de la planta, la densidad de los frutos en el racimo y el tamaño de los frutos (TAM-FRUT). Los accesos más divergentes fueron AP3 y A-P2.

Palabras clave: Guaraná; Mejora Genética; Diversidade.

\section{INTRODUÇÃO}

A produção brasileira de guaraná estimada para 2015 pelo IBGE é de 3,6 mil toneladas, em uma área colhida de 11.796 hectares. O Estado da Bahia, que conta com 15 mil famílias produtoras do fruto, lidera o ranking, com estimativa de produção de 2,6 mil toneladas no ano de 2015, seguido pelo Amazonas, com 855 toneladas. A indústria de refrigerantes e sucos é atualmente o grande mercado para o guaraná e a tendência é que a demanda pelo fruto para este nicho continue crescendo. Mas não é só isso: as indústrias de fármacos e cosméticos são segmentos promissores para exploração econômica do guaraná como fonte de cafeína. Além das possibilidades comerciais no Brasil, há também mercado a ser explorado no exterior, que cada vez mais se interessa pelas propriedades do fruto.

Em função do longo ciclo da cultura, o lançamento de novos materiais genéticos pode levar de 20 a 30 anos. Baseado nessas características é de grande importância o conhecimento da variabilidade e da herança de caráteres de interesse para o melhorista na escolha dos métodos mais adequados na seleção de materiais, tanto nas fases jovem quando na fase adulta (Nascimento Filho e Atroch, 2002).

Os descritores morfoagrônomicos mais utilizados para o guaraná são: características da planta - arquitetura; características da folha - forma, cor da folha jovem, pigmentação antocianínica, coloração verde da folha, intensidade da pigmentação antocianínica, bulado da superfície da face superior do limbo foliar, brilho da face superior, rudimentos foliares na raquis, forma dos rudimentos foliares na raquis; características do racemo - densidade de frutos; características do fruto - forma,

Revista Ouricuri, Juazeiro, Bahia, v.10, n.1. p.027-037. jan./jul., 2020.

http://www.revistas.uneb.br/index.php/ouricuri | ISSN 2317-0131 
coloração, superfície do pericarpo, intensidade do brilho e época de maturação dos frutos (Nascimento Filho et al., 2001).

Além de importantes para o conhecimento da variabilidade genética das populações, estudos de divergência genética possibilitam o monitoramento de bancos de germoplasma, pois geram informações úteis para preservação e uso dos acessos (Elias et al., 2007). Esses estudos auxiliam a identificação de possíveis duplicatas, e fornecem parâmetros para escolha de progenitores, que ao serem cruzados, possibilitarão maior efeito heterótico na progênie, isto é, aumentam as chances de obtenção de genótipos superiores em gerações segregantes (Toquica et al., 2003).

A técnica de análise multivariada tem sido empregada tanto para características expressas por variáveis quantitativas quanto qualitativas, as quais são comumente utilizadas em caracterizações/avaliações em bancos de germoplasma. No caso dos descritores qualitativos geralmente são avaliados os que apresentam várias classes, ou seja, multicategóricos (Pereira et al., 2003; Cruz et al., 2012).

A análise de agrupamento, segundo Cruz et al. (2012), tem por finalidade reunir, por algum critério de classificação, os progenitores (ou qualquer outro tipo de unidade amostral) em vários grupos, de tal forma que exista homogeneidade dentro do grupo e heterogeneidade entre grupos.

O presente trabalho teve como objetivo avaliar 11 acessos de guaranazeiro, por meio da análise de agrupamento com a utilização de dados qualitativos, bem como detectar os caracteres que mais contribuíram para divergência genética.

\section{MATERIAL E MÉTODOS}

Na tabela 1, são apresentados os 11 acessos de guaraná (Paullinia cupana) avaliados, pertencentes a fazenda Nova Esperança localizada no município de Taperoá-BA, a uma latitude de $13^{\circ} 33^{\prime} 27^{\prime \prime}$ Sul e a uma longitude de 39॰10'53" Oeste.

Foram avaliados 18 caracteres qualitativos: Arquitetura da planta (ARQUI); planta: comprimento dos ramos (CRAM); forma da folha (FF); cor da folha jovem (CFJ); pigmentação antocianínica da folha (PIG-NA-FO); coloração verde da folha (CVFOLH); intensidade da pigmentação antocianínica da folha (INT-ANTOC); bulado da superfície da face superior do limbo da folha (SSL); Folha: brilho da face superior (BFS); rudimentos foliares na raquis (RFR); forma dos rudimentos foliares na raquis (FRFR); racemo: densidade de frutos (R-DES-FR); racemo: comprimento do racemo (C-RAC); forma dos frutos (F-FRUT); coloração dos frutos (COL-FRUT); superfície do pericarpo do fruto (S-P-FRUT); intensidade do brilho do fruto (I-B-FRUT) e tamanho do fruto (TAM-FRUT). Para mensuração dos dados foram utilizadas, trena de $5 \mathrm{~m}$, Gps Garmin Etrex 10, Catalogo de cores e prancheta de anotações. As fotografias foram registradas com a Câmera fotográfica Sony Saber Short modelo DSC-W220. 
Foram calculadas as frequências percentuais de cada categoria e o nível de entropia dos caracteres por meio do coeficiente de entropia de Renyi (Renyi, 1961). As análises foram realizadas pelo programa estatístico R (R Core Team, 2016).

A medida de distância utilizada para os descritores multicategóricos avaliados foi a distância de Cole-Rodgers (Cole-Rodgers et al.,1997) obtida no programa Genes (Cruz, 2016). Onde o agrupamento hierárquico das análises a partir da matriz de distância genética foi obtido pelo método de UPGMA - Unweighted Pair Group Method with Arithmetic Mean (Sneath e Sokal, 1973). A consistência do agrupamento foi determinada pelo coeficiente de correlação cofenético de acordo com Sokal e Rohlf (1962). A significância do coeficiente de correlação cofenético foi calculada pelo teste de Mantel com 10.000 permutações, utilizando o programa Genes (Cruz, 2016). O dendrograma foi obtido pelo programa Statistica 7.0 (Statsoft, 2005). Nesse estudo foi usado o índice pseudo- $\mathrm{t}^{2}$ para a determinação do número de grupos obtido pelo Pacote NbClust (Charrad et al., 2016) do programa estatístico R (R Core Team, 2016).

Tabela 1. Descritores qualitativos de 11 acessos de guaranazeiro avaliados e suas respectivas classes.

\begin{tabular}{|c|c|c|}
\hline Descritor qualitativo & Siglas & Classes \\
\hline Planta: arquitetura & ARQUI & $\begin{array}{c}\text { Semi-ereta } \\
\text { Decumbente } \\
\text { Ereta }\end{array}$ \\
\hline Planta: comprimento dos ramos & CRAM & $\begin{array}{l}\text { Longo } \\
\text { Médio } \\
\text { Curto }\end{array}$ \\
\hline Folha: forma & FF & $\begin{array}{c}\text { Elíptica } \\
\text { Oval } \\
\text { Oblonga } \\
\end{array}$ \\
\hline Folha: cor da folha jovem & CFJ & $\begin{array}{c}\text { Verde claro } \\
\text { Verde escura } \\
\text { Verde arroxeado } \\
\text { Marrom } \\
\text { Púrpura }\end{array}$ \\
\hline Folha: pigmentação antocianínica & PIG-NA-FO & $\begin{array}{l}\text { Presente } \\
\text { Ausente }\end{array}$ \\
\hline Folha: coloração verde da folha & CVFOLH & $\begin{array}{c}\text { Clara } \\
\text { Média } \\
\text { Escura } \\
\text { Amarelada }\end{array}$ \\
\hline Folha: intensidade da pigmentação antocianínica & INT-ANTOC & $\begin{array}{c}\text { Baixa } \\
\text { Média } \\
\text { Alta }\end{array}$ \\
\hline Folha: bulado da superfície da face superior do limbo & SSL & $\begin{array}{l}\text { Fraco } \\
\text { Médio } \\
\text { Forte }\end{array}$ \\
\hline Folha: brilho da face superior & BFS & $\begin{array}{l}\text { Fraco } \\
\text { Médio } \\
\text { Forte }\end{array}$ \\
\hline
\end{tabular}




\begin{tabular}{|c|c|c|}
\hline Folha: rudimentos foliares na raquis & RFR & $\begin{array}{l}\text { Presente } \\
\text { Ausente }\end{array}$ \\
\hline Folha: forma dos rudimentos foliares na raquis & FRFR & $\begin{array}{c}\text { Alada } \\
\text { Marginada } \\
\text { Exalada }\end{array}$ \\
\hline Racemo: densidade de frutos & R-DES-FR & $\begin{array}{c}\text { Baixa } \\
\text { Médio } \\
\text { Alta }\end{array}$ \\
\hline Racemo: comprimento & C-RAC & $\begin{array}{c}\text { Longo } \\
\text { Curto } \\
\text { Médio }\end{array}$ \\
\hline Fruto: forma & F-FRUT & $\begin{array}{l}\text { Obovada } \\
\text { Globosa }\end{array}$ \\
\hline Fruto: coloração & COL-FRUT & $\begin{array}{c}\text { Amarela } \\
\text { Alaranjado } \\
\text { Amarela avermelhada, } \\
\text { Vermelha amarelada } \\
\text { Vermelha alaranjada } \\
\text { Vermelha } \\
\text { Vermelha escura }\end{array}$ \\
\hline Fruto: superfície do pericarpo & S-P-FRUT & $\begin{array}{c}\text { Liso } \\
\text { Rugosa }\end{array}$ \\
\hline Fruto: intensidade do brilho & I-B-FRUT & $\begin{array}{c}\text { Fraca } \\
\text { Média } \\
\text { Forte }\end{array}$ \\
\hline Fruto: tamanho & TAM-FRUT & $\begin{array}{c}\text { Médio } \\
\text { Grande } \\
\text { Pequeno }\end{array}$ \\
\hline
\end{tabular}

\section{RESULTADOS E DISCUSSÃO}

$\mathrm{Na}$ tabela 2, estão apresentados os descritores qualitativos, suas classes fenotípicas, frequência percentual dos acessos em cada uma das classes e o nível de entropia de Renyi.

Os descritores que não foram capazes de diferir os acessos são apresentados na análise de entropia com uma frequência de $100 \%$ para uma só classe, apresentando nível de entropia igual a zero (Tabela 2): pigmentação antocianínica da folha (PIG-NA-FO), intensidade da pigmentação antocianínica da folha (INT-ANTOC), brilho da face superior da folha (BFS) e superfície do pericarpo do fruto (S-P-FRUT).

Verifica-se que os descritores que apresentaram maiores valores de entropia estão relacionadas ao comprimento do racemo (C-RAC): $(H=1,07)$, coloração verde da folha (CVFOLH): $(H=1,04)$, forma da folha $(F F)$ : $(H=0,93)$, comprimento dos ramos (CRAM): $(H=0,92)$, arquitetura da planta (ARQUI): $(H=0,86)$, densidade de frutos no racemo (R-DES-FR): $(H=0,86)$, e o tamanho do fruto (TAM-FRUT): $(\mathrm{H}=0,86)$. Em função de apresentarem elevado número de classes e um maior equilíbrio na proporção entre a frequência dos acessos nas diferentes classes fenotípicas, fica evidenciado presença de variabilidade genética entre os acessos estudados (Tabela 2). A entropia de um determinado descritor será tão maior quanto maior for o número de classes fenotípicas desse 
e quanto mais equilibrada for a proporção entre a frequência dos acessos nas diferentes classes fenotípicas. Ou seja, para um descritor morfológico com duas classes fenotípicas, a maior entropia ocorrerá quando ambas as classes apresentarem $50 \%$ dos acessos avaliados (Vieira et al., 2008).

Os descritores que apresentaram os menores valores em relação ao nível de entropia foram: intensidade do brilho do fruto (I-B-FRUT): $(H=0,30)$, rudimentos foliares na raquis (RFR): $(H=0,47)$, forma dos rudimentos foliares na raquis (FRFR): $(\mathrm{H}=0,47)$, bulado da superfície da face superior do limbo da folha (SSL): $(H=0,59)$ e forma dos frutos (F-FRUT): $(H=0,59)$, (Tabela 2). De acordo com Ledo et al. (2011), o nível de entropia pode ser utilizado para quantificar a variabilidade presente em descritores qualitativos por meio da observação das frequências relativas das classes para cada descritor avaliado. Desta forma, baixos valores para entropia estão associados a uma menor quantidade de classes fenotípicas para o descritor utilizado e a um maior desequilíbrio na proporção entre a frequência dos acessos nas diferentes classes fenotípicas.

Os quatro descritores qualitativos que apresentaram nível de entropia igual a zero não foram inseridos nas análises de agrupamento a seguir.

Tabela 2. Descritores qualitativos avaliados, categorias fenotípicas (classes), frequência percentual e nível de entropia dos acessos de guaraná (Paullinia cupana) estudados.

\begin{tabular}{|c|c|c|c|}
\hline Descritor qualitativo & Classes & $\begin{array}{c}\text { Frequência percentual } \\
(\%)\end{array}$ & Nível de entropia \\
\hline \multirow{3}{*}{ ARQUI } & Semi-ereta & 63,64 & \multirow{3}{*}{0,86} \\
\hline & Decumbente & 27,27 & \\
\hline & Ereta & 9,09 & \\
\hline \multirow{3}{*}{ CRAM } & Longo & 54,55 & \multirow{3}{*}{0,92} \\
\hline & Médio & 36,36 & \\
\hline & Curto & 9,09 & \\
\hline \multirow{3}{*}{$\mathrm{FF}$} & Elíptica & 45,45 & \multirow{3}{*}{0,93} \\
\hline & Oval & 45,45 & \\
\hline & Oblonga & 9,09 & \\
\hline \multirow{5}{*}{ CFJ } & Verde claro & 54,55 & \multirow{5}{*}{0,69} \\
\hline & Verde escura & 0,00 & \\
\hline & Verde arroxeado & 45,45 & \\
\hline & Marrom & 0,00 & \\
\hline & Púrpura & 0,00 & \\
\hline \multirow{2}{*}{ PIG-NA-FO } & Presente & 0,00 & \multirow{2}{*}{0,00} \\
\hline & Ausente & 100,00 & \\
\hline \multirow{4}{*}{ CVFOLH } & Clara & 18,18 & \multirow{4}{*}{1,04} \\
\hline & Média & 45,45 & \\
\hline & Escura & 36,36 & \\
\hline & Amarelada & 0,00 & \\
\hline \multirow{3}{*}{ INT-ANTOC } & Baixa & 100,00 & \multirow{3}{*}{0,00} \\
\hline & Média & 0,00 & \\
\hline & Alta & 0,00 & \\
\hline \multirow{3}{*}{ SSL } & Fraco & 27,27 & \multirow{3}{*}{0,59} \\
\hline & Médio & 72,73 & \\
\hline & Forte & 0,00 & \\
\hline BFS & $\begin{array}{l}\text { Fraco } \\
\text { Médio }\end{array}$ & $\begin{array}{c}0,00 \\
100.00\end{array}$ & 0,00 \\
\hline
\end{tabular}

Revista Ouricuri, Juazeiro, Bahia, v.10, n.1. p.027-037. jan./jul., 2020. 


\begin{tabular}{|c|c|c|c|}
\hline & Forte & 0,00 & \\
\hline \multirow{2}{*}{ RFR } & Presente & 18,18 & \multirow{2}{*}{0,47} \\
\hline & Ausente & 81,82 & \\
\hline \multirow{3}{*}{ FRFR } & Alada & 0,00 & \multirow{3}{*}{0,47} \\
\hline & Marginada & 18,18 & \\
\hline & Exalada & 81,82 & \\
\hline \multirow{3}{*}{ R-DES-FR } & Baixa & 63,64 & \multirow{3}{*}{0,86} \\
\hline & Médio & 27,27 & \\
\hline & Alta & 9,09 & \\
\hline \multirow{3}{*}{ C-RAC } & Longo & 45,45 & \multirow{3}{*}{1,07} \\
\hline & Curto & 27,27 & \\
\hline & Médio & 27,27 & \\
\hline \multirow{2}{*}{ F-FRUT } & Obovada & 27,27 & \multirow{2}{*}{0,59} \\
\hline & Globosa & 72,73 & \\
\hline \multirow{7}{*}{ COL-FRUT } & Amarela & 0,00 & \multirow{7}{*}{0,66} \\
\hline & Alaranjado & 63,64 & \\
\hline & Amarela avermelhada, & 0,00 & \\
\hline & Vermelha amarelada & 0,00 & \\
\hline & Vermelha alaranjada & 36,36 & \\
\hline & Vermelha & 0,00 & \\
\hline & Vermelha escura & 0,00 & \\
\hline \multirow{2}{*}{ S-P-FRUT } & Liso & 100,00 & \multirow{2}{*}{0,00} \\
\hline & Rugosa & 0,00 & \\
\hline \multirow{3}{*}{ I-B-FRUT } & Fraca & 0,00 & \multirow{3}{*}{0,30} \\
\hline & Média & 90,91 & \\
\hline & Forte & 9,09 & \\
\hline \multirow{3}{*}{ TAM-FRUT } & Médio & 63,64 & \multirow{3}{*}{0,86} \\
\hline & Grande & 27,27 & \\
\hline & Pequeno & 9,09 & \\
\hline
\end{tabular}

Arquitetura da planta (ARQUI); planta: comprimento dos ramos (CRAM); forma da folha (FF); cor da folha jovem (CFJ); pigmentação antocianínica da folha (PIG-NA-FO); coloração verde da folha (CVFOLH); intensidade da pigmentação antocianínica da folha (INT-ANTOC); bulado da superfície da face superior do limbo da folha (SSL); Folha: brilho da face superior (BFS); rudimentos foliares na raquis (RFR); forma dos rudimentos foliares na raquis (FRFR); racemo: densidade de frutos (RDES-FR); racemo: comprimento do racemo (C-RAC); forma dos frutos (F-FRUT); coloração dos frutos (COL-FRUT); superfície do pericarpo do fruto (S-P-FRUT); intensidade do brilho do fruto (IB-FRUT) e tamanho do fruto (TAM-FRUT).

As medidas de dissimilaridade genética (Tabela 3), estimadas a partir da distância de ColeRodgers, apresentaram uma magnitude de 0,29 a 0,86, indicando presença de variabilidade genética entre os genótipos em relação aos 14 descritores qualitativos estudados.

Os acessos mais divergentes foram o A-P3 x A-P2, obtendo a máxima distância com valor de $(D=0,86)$, esses acessos diferem para várias características avaliadas: Arquitetura da planta (ARQUI); forma da folha (FF); coloração verde da folha (CVFOLH); bulado da superfície da face superior do limbo da folha (SSL); rudimentos foliares na raquis (RFR); forma dos rudimentos foliares na raquis (FRFR); Racemo: densidade de frutos (R-DES-FR); forma dos frutos (F-FRUT) e coloração dos frutos (COL-FRUT). 
Já a menor distância foi observada entre os acessos A-P7 com o A-P4 e A-P6) e entre o AP5 e os acessos A-P9, A-P10 e A-P11, essas combinações apresentaram o valor mínimo de $(D=$ $0,29)$.

Tabela 3. Matriz de dissimilaridade genética entre os 11 acessos de guaraná (Paullinia cupana), baseado na distância de cole Rodgers, em relação a 14 descritores qualitativos.

\begin{tabular}{|c|c|c|c|c|c|c|c|c|c|c|}
\hline Acessos & A-P1 & A-P2 & A-P3 & A-P4 & A-P5 & A-P6 & A-P7 & A-P8 & A-P9 & A-P10 \\
\hline A-P2 & 0.64 & & & & & & & & & \\
\hline A-P3 & 0.36 & 0.86 & & & & & & & & \\
\hline A-P4 & 0.79 & 0.36 & 0.64 & & & & & & & \\
\hline A-P5 & 0.64 & 0.57 & 0.57 & 0.50 & & & & & & \\
\hline A-P6 & 0.57 & 0.64 & 0.50 & 0.50 & 0.43 & & & & & \\
\hline A-P7 & 0.64 & 0.50 & 0.43 & 0.29 & 0.50 & 0.29 & & & & \\
\hline A-P8 & 0.57 & 0.43 & 0.71 & 0.43 & 0.36 & 0.43 & 0.43 & & & \\
\hline A-P9 & 0.71 & 0.50 & 0.57 & 0.64 & 0.29 & 0.64 & 0.57 & 0.43 & & \\
\hline A-P10 & 0.50 & 0.79 & 0.36 & 0.50 & 0.29 & 0.36 & 0.43 & 0.50 & 0.57 & \\
\hline A-P11 & 0.64 & 0.64 & 0.50 & 0.57 & 0.29 & 0.36 & 0.50 & 0.36 & 0.43 & 0.43 \\
\hline
\end{tabular}

O coeficiente de correlação cofenético (CCC) foi significativo com $\left(r=0,66^{* *}\right)$, indicando um bom ajuste e consistência da análise de agrupamento em relação à matriz de dissimilaridade. Para Monteiro et al. (2010), quanto mais próximo da unidade, melhor a representação da matriz de dissimilaridade na forma de dendrograma. Alguns autores justificam que coeficientes com valores compreendidos entre 0,60 e 0,80 são provenientes do pequeno número de variáveis utilizadas. Contudo, sabe-se que existem outros fatores que também podem influenciar nos valores dos coeficientes como a qualidade dos dados obtidos (Neves, 2013).

No agrupamento dos acessos pelo método UPGMA, representado no dendrograma (Figura 1) a partir da matriz de dissimilaridade da distância de Cole-Rodgers, com o ponto de corte definido por meio do índice pseudo-t ${ }^{2}$, foi detectado a formação de 2 grupos: $O$ grupo I é formado por 9 acessos, (A-P2; A-P4; A-P5; A-P6; A-P7; A-P8; A-P9; A-P10 e A-P11) esse grupo agrega acessos com características distintas do grupo II, por apresentarem plantas com arquitetura ereta e decumbente, forma da folha elíptica a oblonga, coloração verde da folha na maioria das plantas com tom escuro, não apresenta presença de rudimentos foliares na raquis, densidade de frutos no racemo de média a alta e forma globosa na grande maioria dos frutos, forma exalada dos rudimentos foliares na raquis e plantas com comprimento do racemo de curto a longo. 


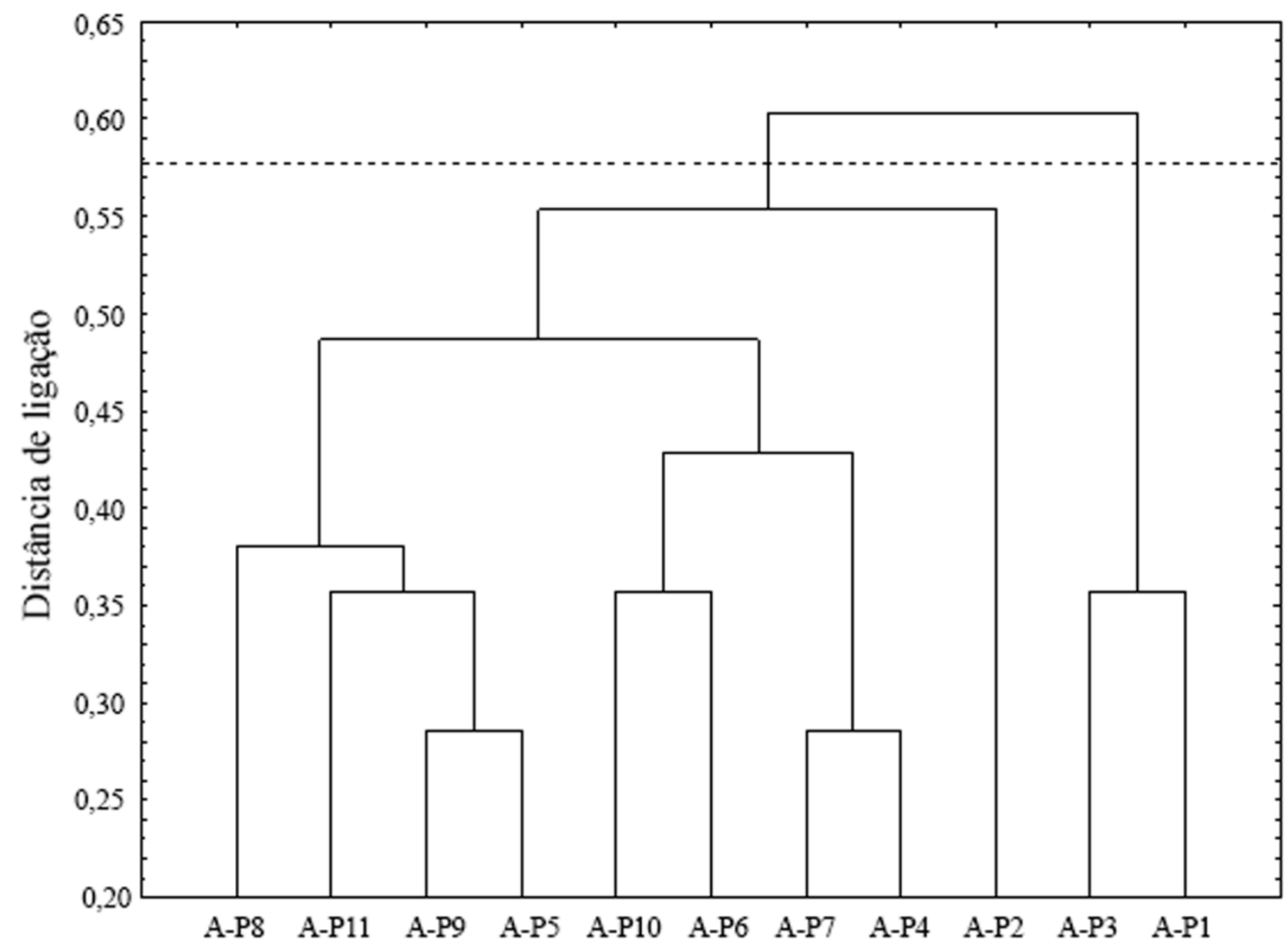

Figura 1. Dendrograma de dissimilaridade genética entre 11 acessos de guarazeiro resultante do agrupamento pelo método UPGMA obtido pela distância de Cole-Rogers estimados em 14 descritores qualitativos.

Já o grupo II é constituído por dois acessos (A-P1 e o A-P3). Esse grupo se caracteriza principalmente pelas peculiaridades de presença de rudimentos foliares na raquis e forma marginada dos rudimentos foliares na raquis.

$\mathrm{Na}$ escolha de indivíduos para cruzamento genético, deve-se evitar a escolha de indivíduos de mesmo padrão de dissimilaridade nos cruzamentos, de modo a não restringir a variabilidade genética, e assim, evitar reflexos negativos nos ganhos a serem obtidos pela seleção. Aliado ao padrão de dissimilaridade, deve-se avaliar o bom desempenho dos genitores nas características que se deseja melhorar (Silva et al., 2012).

\section{CONCLUSÕES}

Foi detectada variabilidade genética entre os acessos estudados, e os acessos mais divergentes foram o A-P3 e o A-P2.

Os descritores que mais contribuíram para divergência entre os acessos estudados foram o comprimento do racemo (C-RAC), coloração verde da folha (CVFOLH), forma da folha (FF), 
comprimento dos ramos (CRAM), arquitetura da planta (ARQUI), densidade de frutos no racemo (R-DES-FR) e o tamanho do fruto (TAM-FRUT).

\section{REFERÊNCIAS}

Charrad, N.; Ghazzali, N.; Boiteau, V.; Niknafs, A. NbClust: NbClust package for determining the best number of clusters. $R$ package version 2.0.1. Disponível em: http://CRAN.Rproject.org/package=NbClust. Acesso em 20 jun. 2016.

Cole-Rodgers, P.; Smith, D. W.; Bosland, P. W. A novel statistical approach to analyze genetic resource evaluations using Capsicum as an example. Crop Science, 37, 1000 - 1002, 1997.

Cruz, C. D. Programa Genes - Aplicativo computacional em genética e estatística. Disponível em: www.ufv.br/dbg/genes/genes.htm. Acesso em 20 jul. 2018.

Cruz, C. D.; Regazzi, A. J.; Carneiro, P. C. S. Modelos biométricos aplicados ao melhoramento genético. 4. ed. Viçosa: Editora UFV, 2012.

Elias, H. T.; Vidigal, M. C. G.; Gonela, A; Vogt, G. A. Variabilidade genética em germoplasma tradicional de feijão-preto em Santa Catarina. Pesquisa Agropecuária Brasileira, 42(10), 1443-1449, 2007.

Ledo, C. A. S.; Alves, A. A. C.; Silveira, T. C.; Oliveira, M. M.; Santos, A. S.; Tavares Filho, L. F. Q. Caracterização morfológica da coleção de espécies silvestres de Manihot (Euphorbiaceae Magnoliophyta) da Embrapa Mandioca e Fruticultura. Boletim de Pesquisa e Desenvolvimento. Embrapa Mandioca e Fruticultura, v.53, dezembro, 2011.

Monteiro, E. R.; Bastos, E. M.; Lopes, Â. C. A.; Gomes, R. L. F.; Nunes. J. A. R. Diversidade genética entre acessos de espécies cultivadas de pimentas. Ciência Rural, 40(2), 288-293, 2010.

Nascimento Filho, F. J.; Atroch, A. L. Guaranazeiro. In: Brukner, C. H. Melhoramento de fruteiras tropicais. Vicosa: Editora UFV, 2002, p. 291-307.

Nascimento Filho, F. J.; Atroch, A. L.; Souza, N. R.; Garcia, T. B.; Cravo, M. S.; Coutinho, E. F. Divergência genética entre clones de guaranazeiro. Pesquisa Agropecuária Brasileira, 36(3), 501506, 2001.

Neves, C. G.; Jesus, O. N.; Ledo, C. A. S.; Oliveira, E. J. Avaliação agronômica de parentais e híbridos de maracujazeiro- amarelo. Revista Brasileira de Fruticultura, 35(1), 191-198, 2013.

Pereira, F. H. F.; Puiatti, M.; Miranda, G. V.; Silva, D. J. H.; Finger, F. L. Divergência genética entre acessos de taro utilizando caracteres morfoqualitativos de inflorescência. Horticultura Brasileira, 21(1), 116-118, 2003.

R Core Team. R: A language and environment for statistical computing. R Foundation for Statistical Computing, Vienna, Austria. 2016. Disponível em: http://www.R-project.org/. Acesso em 15 jul. 2018.

Rényi, A. On Measures of Entropy and Information. Proceedings of the Fourth Berkeley Symposium on Mathematical Statistics and Probability, Volume 1: Contributions to the Theory of Statistics, 547-561, University of California Press, Berkeley, Calif., 1961. Disponível em: https://projecteuclid.org/euclid.bsmsp/1200512181. Acesso em 15 jul. 2020.

Silva, J. F.; Bertini, C. H. C. M.; Bleicher, E.; Moraes, J. G. L. Divergência genética de genótipos de feijão-de-corda quanto à resistência ao pulgão-preto. Pesquisa agropecuária brasileira, 47(7), 948954, 2012. 
Sneath, P. H.; Sokal, R. R. Numerical taxonomy: The principles and practice of numerical classification. 1. ed. San Francisco: W.H. Freeman, 1973.

Sokal, R. R.; Rohlf, F. J. The comparison of dendrograms by objective methods. Taxon, 11, 33-40. 1962.

Statsoft, Inc. Statistica for Windows (data analysis software system), version 7.1. Statsoft, Tulsa, Oklahoma (USA), 2005.

Toquica, S. P.; Rodríguez, F.; Martínez, E.; Duque, C.; Tohme, J. Molecular characterization by AFLPs of Capsicum germplasm from the Amazon Departmente in Colombia, Characterization by AFLPs of Capsicum. Genétic Resources and Crop Evolution, 50, 639-647, 2003.

Vieira, E. A.; Fialho, J. F.; Silva, M. S.; Fukuda, W. M. G.; Faleiro, F. G. Variabilidade genética do banco de germoplasma de mandioca da Embrapa Cerrados acessada por meio de descritores morfológicos. Científica, 36, 56-67, 2008. 